\title{
Effects of bioaugmentation in para-nitrophenol-contaminated soil on the abundance and community structure of ammonia-oxidizing bacteria and archaea
}

\author{
Xiang-Qun Chi $\cdot$ Kun Liu $\cdot$ Ning-Yi Zhou
}

Received: 30 October 2014 / Revised: 3 February 2015 / Accepted: 5 February 2015 / Published online: 1 March 2015

(C) Springer-Verlag Berlin Heidelberg 2015

\begin{abstract}
Pseudomonas sp. strain WBC-3 mineralizes the priority pollutant para-nitrophenol (PNP) and releases nitrite $\left(\mathrm{NO}_{2}{ }^{-}\right)$, which is probably involved in the nitrification. In this study, the rate of PNP removal in soil bioaugmented with strain WBC-3 was more accelerated with more $\mathrm{NO}_{2}{ }^{-}$accumulation than in uninoculated soils. Strain WBC-3 survived well and remained stable throughout the entire period. Realtime polymerase chain reaction (real-time PCR) indicated a higher abundance of ammonia-oxidizing bacteria (AOB) than ammonia-oxidizing archaea (AOA), suggesting that $\mathrm{AOB}$ played a greater role in nitrification in the original sampled soil. Real-time PCR and multivariate analysis based on the denaturing gradient gel electrophoresis showed that PNP contamination did not significantly alter the abundance and community structure of ammonia oxidizers except for inhibiting the AOB abundance. Bioaugmentation of PNP-contaminated soil showed a significant effect on AOB populations and community structure as well as AOA populations. In addition, ammonium $\left(\mathrm{NH}_{4}{ }^{+}\right)$variation was found to be the primary factor affecting the AOB community structure, as determined
\end{abstract}

X.-Q. Chi • N.-Y. Zhou $(\bowtie)$

Key Laboratory of Agricultural and Environmental Microbiology,

Wuhan Institute of Virology, Chinese Academy of Sciences,

Wuhan 430071, China

e-mail:n.zhou@pentium.whiov.ac.cn

X.-Q. Chi

Research Center for Marine Biology and Carbon Sequestration, Qingdao Institute of Bioenergy and Bioprocess Technology, Chinese Academy of Sciences, Qingdao 266101, China

K. Liu $\cdot$ N.-Y. Zhou

State Key Laboratory of Microbial Metabolism and School of Life

Sciences and Biotechnology, Shanghai Jiao Tong University,

Shanghai 200240, China by the correlation between the community structures of ammonia oxidizers and environmental factors. It is here proposed that the balance between archaeal and bacterial ammonia oxidation could be influenced significantly by the variation in $\mathrm{NH}_{4}{ }^{+}$levels as caused by bioaugmentation of contaminated soil by a pollutant containing nitrogen.

Keywords Ammonia-oxidizing archaea .

Ammonia-oxidizing bacteria $\cdot$ Bioaugmentation $\cdot$ Multivariate analyses $\cdot$ para-nitrophenol $\cdot$ Pseudomonas sp. strain WBC-3

\section{Introduction}

Ammonia oxidation is performed by both ammonia-oxidizing bacteria $(\mathrm{AOB})$ and ammonia-oxidizing archaea (AOA) (Liu et al. 2013; Prosser and Nicol 2012). The amoA gene encodes the $\alpha$ subunit of ammonia monooxygenase which performs the first and rate-limiting step of the nitrification process in both groups. Quantitative real-time PCR of the amoA gene has indicated that AOA are abundant in a wide range of habitats and may play a greater role in the nitrification process (Prosser and Nicol 2012). However, the magnitudes of the relative contributions of $\mathrm{AOB}$ and $\mathrm{AOA}$, which have ecologically equivalent functions, to ammonia oxidation are still largely unknown. It has been suggested that many environmental factors including $\mathrm{pH}$ (Nicol et al. 2008), salinity (Mosier and Francis 2008), $\mathrm{NH}_{4}{ }^{+}$(Hofferle et al. 2010; Martens-Habbena et al. 2009; Verhamme et al. 2011), and dissolved oxygen concentration (Abell et al. 2011) may play a critical role in their individual dominance and the niche segregation of ammonia oxidizers. These findings have stimulated a reassessment of ammonia-oxidizer community ecology, and consequently, the nitrification process in agricultural ecosystems 
should be re-evaluated. Therefore, an understanding of the response of $\mathrm{AOA}$ and $\mathrm{AOB}$ to particular abiotic and biotic factors within the environment, in particular, the responses of $\mathrm{AOA}$ and $\mathrm{AOB}$ to environment changes are indispensable for the prediction and management of ecosystem functions (Liu et al. 2013).

para-nitrophenol (PNP), one of the three isomeric mononitrophenols, enters the environment through industrial release and the degradation of parathion-based pesticides (Zhang et al. 2009). PNP has been cataloged as priority pollutant by United States Environmental Protection Agency (USEPA) (Keith and Telliard 1979). PNP is highly water soluble and potentially teratogenic, carcinogenic, and mutagenic to many organisms (Guo et al. 2004). It has been reported that polycyclic aromatic hydrocarbons can reduce soil nitrification (Sverdrup et al. 2002) and that nitrobenzene can inhibit nitrification in soil by acting as the ammonium monooxygenase's suicide substrate (Keener and Arp 1994; McCarty 1999; Zhao et al. 2009). In particular, cyclic $\mathrm{N}$ compounds are an important class of nitrification inhibitors because of their N-ring structure (McCarty 1999). In this way, the presence of cyclic $\mathrm{N}$ compounds, such as PNP, in soil is likely to affect the nitrification of ammonium oxidizers.

Bioaugmentation refers to the use of bacterial cultures to speed up the rate of degradation of a contaminant. This is generally regarded as a promising way to remove contaminants from soils (Dechesne et al. 2005). It has been used previously for remediating PNP-contaminated soil (Labana et al. 2005). The soil bacterium Pseudomonas sp. strain WBC-3 [China Center for Type Culture Collection (CCTCC) M201027] can utilize PNP as the sole source of carbon, nitrogen, and energy, with the concomitant release of $\mathrm{NO}_{2}{ }^{-}$(Zhang et al. 2009). $\mathrm{NO}_{2}{ }^{-}$was once thought to be a determining factor in the niche variation between AOA and AOB (Sahan and Muyzer 2008). High $\mathrm{NO}_{2}^{-}$concentrations may be toxic to AOA (Wuchter et al. 2006). Possibly because of the release of $\mathrm{NO}_{2}{ }^{-}$, a dynamic bioaugmentation process of PNPcontaminated soil inoculated with strain WBC-3 may interfere with nitrification processes and the nitrogen cycling in the contaminated sites. For this reason, the response of AOB and AOA to PNP contamination and the bioaugmentation process is an important avenue of investigation.

To date, most studies on the factors affecting the niche separation of nitrifying bacteria and archaea have focused on specific soil properties such as soil $\mathrm{pH}$ value (Nicol et al. 2008) and dissolved oxygen (Abell et al. 2011), but there is little information available regarding the response and adaption of $\mathrm{AOB}$ and $\mathrm{AOA}$ to dynamic bioaugmentation processes when the elements involved are converted from one substance to another, particularly when the elements are channeled into the nitrogen cycle. Information regarding the effects of such a dynamic bioaugmentation process on ammonia-oxidizer community composition and activity will be important for understanding their niche specialization. For this reason, the current study aimed to (i) investigate the responses of the abundance and community structure of $\mathrm{AOB}$ and AOA to persistent PNP contamination and dynamic bioaugmentation processes and (ii) determine the primary abiotic and biotic factors within the environment that result in the niche differentiation of $\mathrm{AOB}$ and $\mathrm{AOA}$ in soil.

\section{Materials and methods}

Soil sample collection and characteristics

Soil samples were taken from the paddy experimental field $\left(30^{\circ} 28^{\prime} 09^{\prime \prime} \mathrm{N}, 114^{\circ} 20^{\prime} 54^{\prime \prime} \mathrm{E}\right)$ in Huazhong Agricultural University, Wuhan, China, which had no history of PNP contamination. This field was established using a rice-rape rotation system, in which the first growing season, forrice, was from May to August and the second season, forrape, was from September to May of the next year. The top layer $(0-15 \mathrm{~cm})$ of the soil was sampled in October of rape planting season in 2010 when the soil was well-drained and the weather was fine. The soil samples were sieved $(\leq 2 \mathrm{~mm})$ and kept at $4{ }^{\circ} \mathrm{C}$. Soil total carbon content was $0.88 \pm 0.10 \%$, and total nitrogen content was $0.09 \pm 0.01 \%$. The soil $\mathrm{pH}$ was $7.11 \pm 0.12$, and water content was $18.11 \pm 0.43 \%$.

\section{Preliminary experiments}

Initially, five different concentrations $(0.10,0.25,0.50,0.75$, and $1.00 \mathrm{mg} \mathrm{g}^{-1}$ dry weight (dw)) of PNP were set up in both contamination and bioaugmentation treatments. It was shown that PNP had been removed completely when the concentration reached $0.50 \mathrm{mg} \mathrm{g}^{-1} \mathrm{dw}$ or lower. In all subsequent experiments, PNP at a final concentration of $0.40 \mathrm{mg} \mathrm{g}^{-1} \mathrm{dw}$ was selected and added to soil samples.

\section{Soil microcosm experiments}

Soil samples corresponding to $100 \mathrm{~g}$ dry weight were sterilized in glass bottles $(250 \mathrm{~mL})$ with tightened caps using three rounds of autoclaving $\left(20 \mathrm{~min}\right.$ at $\left.121^{\circ} \mathrm{C}\right)$ on three consecutive days. Four treatment groups were established: (T1) natural soil, (T2) natural soil with PNP added, (T3) natural soil with PNP added and strain WBC-3 (CCTCCM201027) inoculated and, (T4) sterile soil with PNP added. All subsequent settings of different treatments were prepared as described by Chi et al. (2013).

Chemical analysis

PNP concentration was monitored using high-performance liquid chromatography (HPLC) as described by Chi et al. 
(2013). In detail, PNP was assessed using an Agilent series 1200 system (Agilent Technologies, Palo Alto, CA, USA) equipped with a $\mathrm{C}_{18}$ reversed-phase column $(5 \mu \mathrm{m}, 4.6 \times$ $250 \mathrm{~mm}$; Agilent Technologies) maintained at $30{ }^{\circ} \mathrm{C}$. The mobile phase consisted of methanol (40\%) and $0.1 \%$ acetic acid $(60 \%)$ at a flow rate of $1 \mathrm{~mL} \mathrm{~min}^{-1}$. PNP was monitored at $280 \mathrm{~nm}$ with an Agilent ultraviolet detector, and its retention time was $11.2 \mathrm{~min}$. The $\mathrm{NH}_{4}{ }^{+}$(Fawcett and Scott 1960) and $\mathrm{NO}_{2}{ }^{-}$(Lessner et al. 2002) concentrations were colorimetrically detected (Chi et al. 2013). The concentration of nitrate $\left(\mathrm{NO}_{3}{ }^{-}\right)$was determined as described by Norman et al. (1985). For $\mathrm{NO}_{3}{ }^{-}$determination, $0.5 \mathrm{~g}$ each soil samples were extracted using $3 \mathrm{~mL}$ saturated $\mathrm{KCl}$ solution and then shaken for $30 \mathrm{~min}$ at $200 \mathrm{rpm}$, before the samples were centrifuged at $10,000 \times g$ for $10 \mathrm{~min}$.

\section{DNA extraction}

Here, $0.5 \mathrm{~g}$ soil samples were used to extract DNA with MoBio Ultra Clean ${ }^{\mathrm{TM}}$ soil DNA isolation kit (MoBio Laboratories, Carlsbad, CA), in accordance with the manufacturer's instructions.

\section{Quantitative real-time PCR}

Quantitative real-time PCR was performed on a CFX Connect $^{\mathrm{TM}}$ Optics (Bio-Rad Labs, Hercules, CA, USA) using the probe and primers listed in Table 1. The pnpA gene encodes the enzyme responsible for the initial degradation of PNP in strain WBC-3. The reaction solution and PCR program used for quantification of the $p n p A$ gene were as described previously (Chi et al. 2013). The probe, primers, and thermal programs used for total bacterial $16 \mathrm{~S}$ ribosomal RNA (rRNA) gene quantification in soil samples were as described previously (Chi et al. 2013; Shen et al. 2008). The amo $A$ gene of $\mathrm{AOB}$ and AOA were quantified as described previously (He et al. 2007; Shen et al. 2008).

\section{PCR-DGGE analyses}

The initial, degradation, and later phases of the microcosms were sampled on days 0,8 , and 28 , respectively. The primer pairs (amoA1F-GC and amoA2R for bacterial amoAgene, Arch-amoAF and Arch-amoAR-GC for archaeal amoAgene), reaction systems, and programs for PCR amplifying the amo $A$ gene fragments of AOB and AOA for denaturing gradient gel electrophoresis (DGGE) analysis were established as in previously published reports (He et al. 2007; Shen et al. 2008).

DGGE was conducted using the Dcode System (Bio-Rad Labs, Hercules, CA, USA) as described by Muyzer et al. (1993). Here, $6 \%$ polyacrylamide gels contained a denaturant gradient of $40-65 \%$ for the amo $A$ gene fragments of AOB and $20-60 \%$ for the $a m o A$ gene fragments of AOA. The gels were run in $1 \times$ TAE buffer for $10 \mathrm{~h}$ at a voltage of $80 \mathrm{~V}$ at $60^{\circ} \mathrm{C}$. Following this, the gels were stained using silver nitrate as reported previously (McCaig et al. 2001). Quantity One 4.62 software (Bio-Rad) was used to analyze the DGGE profiles.

Multivariate analyses

Repeated measures in general linear model and LSD testing were performed using SPSS version 20. This analysis was used to quantify the differences between the AOB and AOA amo $A$ genes for different treatments. $P<0.05$ was considered to be statistically significant, and $P<0.01$ was considered highly statistically significant.

Table 1 Primers and probe used in current study

\begin{tabular}{llll}
\hline Primers & Target & Sequence $\left(5^{\prime}-3^{\prime}\right)$ & Reference \\
\hline pnpA96 & pnpA & CTTCCTTGAACATCGCATCGT & (Chi et al. 2013) \\
pnpA1204 & pnpA & GCTAGATGGAGTCGTTGTAGTTGG & (Chi et al. 2013) \\
pnpA1 & pnpA & CACGCTTGCGGATGTCTTGGAG & (Chi et al. 2013) \\
pnpA2 & pnpA & TCCGGTTGGACTTCTTACTGCACTG & (Chi et al. 2013) \\
BACT1369F & $16 \mathrm{~S}$ rRNA gene & CGGTGAATACGTTCYCGG & (Shen et al. 2008) \\
PROK1541R & $16 \mathrm{~S}$ rRNA gene & AAGGAGGTGATCCRGCCGCA & (Shen et al. 2008) \\
TM1389F & 16S rRNA gene & CTTGTACACACCGCCCGTC & (Shen et al. 2008) \\
amoA1F & AOB & GGGGTTTCTACTGGTGGT & (Shen et al. 2008) \\
amoA2R & AOB & CCCCTCKGSAAAGCCTTCTTC & (Shen et al. 2008) \\
Arch-amoAF & AOA & STAATGGTCTGGCTTAGACG & (He et al. 2007) \\
Arch-amoA & AOA & GCGGCCATCCATCTGTATGT & (He et al. 2007) \\
\hline
\end{tabular}

${ }^{\text {a }}$ Probe

${ }^{\text {b }}$ A 40 bp pair GC clamp (CGCCCGCCGCGCCCCGCGCCCGGCCCGCCGCCCCCGCCCC) was attached to the 5' end of each primer 
Using Canoco software (version 4.5), redundancy analysis (RDA) was used to evaluate the correlation between the AOB/AOA community structures and the environmental parameters. The environmental parameters were divided into two groups of variables: (1) treatment variables (PNP concentration, the abundance of strain WBC- $3, \mathrm{NH}_{4}^{+}, \mathrm{NO}_{3}^{-}$, and $\mathrm{NO}_{2}^{-}$, and the nominal variables of treatments $\mathrm{T} 1, \mathrm{~T} 2$, and $\mathrm{T} 3$ ) and (2) time variables. Standard RDA was used to investigate the variance in species composition with the two groups of environmental parameters as the explanatory variables. Partial RDA (pRDA) was then used to assess the variance explained by each parameter group (i.e., time or treatment parameters) by taking the other group of environmental parameters as covariates. The significance of the models was examined using Monte Carlo permutation at the $5 \%$ level (with 499 unrestricted permutations). Both environmental and species numbers were log-transformed for subsequent analyses (Zhao et al. 2009).

Sequence analyses of amoA genes from DGGE bands

The marked bands with numbers and the other bands with the same position on the DGGE gels were excised. The corresponding amo $A$ genes were extracted for cloning and sequence analysis as described previously (Schwieger and Tebbe 1998). The recovered DNA was re-amplified using the primer pairs (amoA1F-GC and amoA2R for the AOB amoA gene, Arch-amoAF and Arch-amoAR-GC for AOA amoA gene) and then confirmed by DGGE. After that, the amplified products of purified amoA gene were ligated with the pGEM-T vector (Promega) and transformed into Escherichia coli $\mathrm{DH} 5 \alpha$ for sequencing.

Phylogenetic analyses of sequences

BLASTN (http://www.ncbi.nlm.nih.gov) was used to investigate the sequences, determine sequence homology, and identify closest relatives. MEGA 5.02 was used for phylogenetic analyses. The neighbor-joining trees were constructed using the Kimura two-parameter distance, and bootstrap values were produced using 1000 replicates (Shen et al. 2008). All of the $a m o A$ gene sequences were deposited under GenBank accession nos. KM055656-KM055684.

\section{Results}

Bioaugmentation of soil contaminated with PNP

The PNP concentration in different treatments was determined using HPLC. PNP was removed more rapidly in bioaugmentation treatment T3 (native soil + PNP +
WBC-3) than in both uninoculated treatments $\mathrm{T} 2$ (native soil + PNP) and T4 (sterile soil + PNP) (Fig. 1a). In T3, all PNP added $\left(0.04 \mu \mathrm{g} \mathrm{g}^{-1} \mathrm{dw}\right)$ was completely removed after 14 days. In contrast, PNP concentration showed no significant changes in either $\mathrm{T} 2$ or $\mathrm{T} 4$ during the 28-day experimental period $(P>0.05)$ (Fig. 1a).

Because $\mathrm{NO}_{2}^{-}$was released via PNP oxidation by strain WBC-3, the $\mathrm{NO}_{2}{ }^{-}-\mathrm{N}$ concentration was also monitored in the bioaugmentation treatment T3 (native soil + PNP + WBC-3) and in the other treatment groups. As shown in Fig. 1b, in T3, the $\mathrm{NO}_{2}{ }^{-}-\mathrm{N}$ concentration increased gradually to $7.96 \pm$ $2.59 \mu \mathrm{g} \mathrm{g}^{-1} \mathrm{dw}$ in the first 8 days. It subsequently decreased to the original concentration by day 22 . The molar proportion of PNP degradation to the accumulation of $\mathrm{NO}_{2}{ }^{-}-\mathrm{N}$ was about $3: 1$ on day 8 . In all other uninoculated treatment groups, the $\mathrm{NO}_{2}{ }^{-}-\mathrm{N}$ concentration appeared to remain constant across the 28 days (Fig. 1b).

In the bioaugmentation treatment group T3 (native soil + $\mathrm{PNP}+\mathrm{WBC}-3$ ), the $\mathrm{NH}_{4}{ }^{+}-\mathrm{N}$ concentration increased rapidly to a maximum concentration of $37.99 \pm 2.22 \mu \mathrm{g} \mathrm{g}^{-1} \mathrm{dw}$ (Fig. 1c) contaminant with the release of $\mathrm{NO}_{2}^{-}$during PNP degradation (Fig. 1b). After the complete removal of PNP on day $14, \mathrm{NH}_{4}{ }^{+}-\mathrm{N}$ began to decrease gradually to $25.78 \pm$ $15.26 \mu \mathrm{g} \mathrm{g}^{-1} \mathrm{dw}$ on day 28 , still far above the initial level as of the beginning of bioaugmentation $\left(2.53 \pm 0.79 \mu \mathrm{g} \mathrm{g}^{-1} \mathrm{dw}\right)$ (Fig. 1c). In contrast, its $\mathrm{NO}_{3}{ }^{-}-\mathrm{N}$ concentration kept increasing for the entire period, reaching to $65.49 \pm 8.54{\mu \mathrm{g} \mathrm{g}^{-1} \mathrm{dw}}^{\mathrm{d}}$ (Fig. 1d). In T2 (native soil + PNP), although the $\mathrm{NH}_{4}{ }^{+}-\mathrm{N}$ concentration increased gradually to $25.45 \pm 3.14 \mu \mathrm{g} \mathrm{g}^{-1} \mathrm{dw}$, it remained lower than in $\mathrm{T} 3$ at all times except the first 4 days (Fig. 1c). The $\mathrm{NO}_{3}{ }^{-}-\mathrm{N}$ concentration in $\mathrm{T} 2$ decreased steadily to $16.61 \pm 4.17 \mu \mathrm{g} \mathrm{g}^{-1} \mathrm{dw}$ at the end of the experimental period (Fig. 1d). In treatment $\mathrm{T} 1$ (native soil), the $\mathrm{NO}_{3}{ }^{-} \mathrm{N}$ concen-

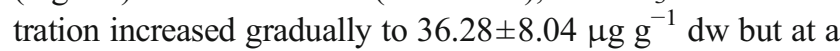
much lower rate than in T3 (Fig. 1d). However, the $\mathrm{NH}_{4}{ }^{+}-\mathrm{N}$ concentration in $\mathrm{T} 1$ showed no obvious change during the entire period and remained at an almost constantly lower level than those in T2 and T3 (Fig. 1c). The high initial $\mathrm{NH}_{4}{ }^{+}-\mathrm{N}$ concentration in $\mathrm{T} 4$ came largely from the autoclaving process of the soil samples (Chi et al. 2013) (Fig. 1c).

The abundance of the inoculated strain WBC-3 in bioaugmentation treatment $\mathrm{T} 3$ was quantified using the copy numbers of the $p п p A$ gene as previously described by Chi et al. (2013). In the first 8 days of PNP removal in T3, the copy numbers of $p n p A$ decreased by approximately two orders of magnitude (from $1.67 \pm 1.08 \times 10^{8}$ on day 0 to $5.48 \pm 5.68 \times 10^{6}$ per gram of dry soil) (Fig. 2). As PNP degraded further, its copy numbers increased to $2.57 \pm 3.12 \times 10^{7}$ per gram of dry soil on day 14 at which time PNP had been removed completely (Fig. 2). It later decreased again by about one order of magnitude to $1.13 \pm 0.91 \times 10^{6}$ per gram of dry soil at day 18 and then remained constant until the end of the experimental period (Fig. 2). 

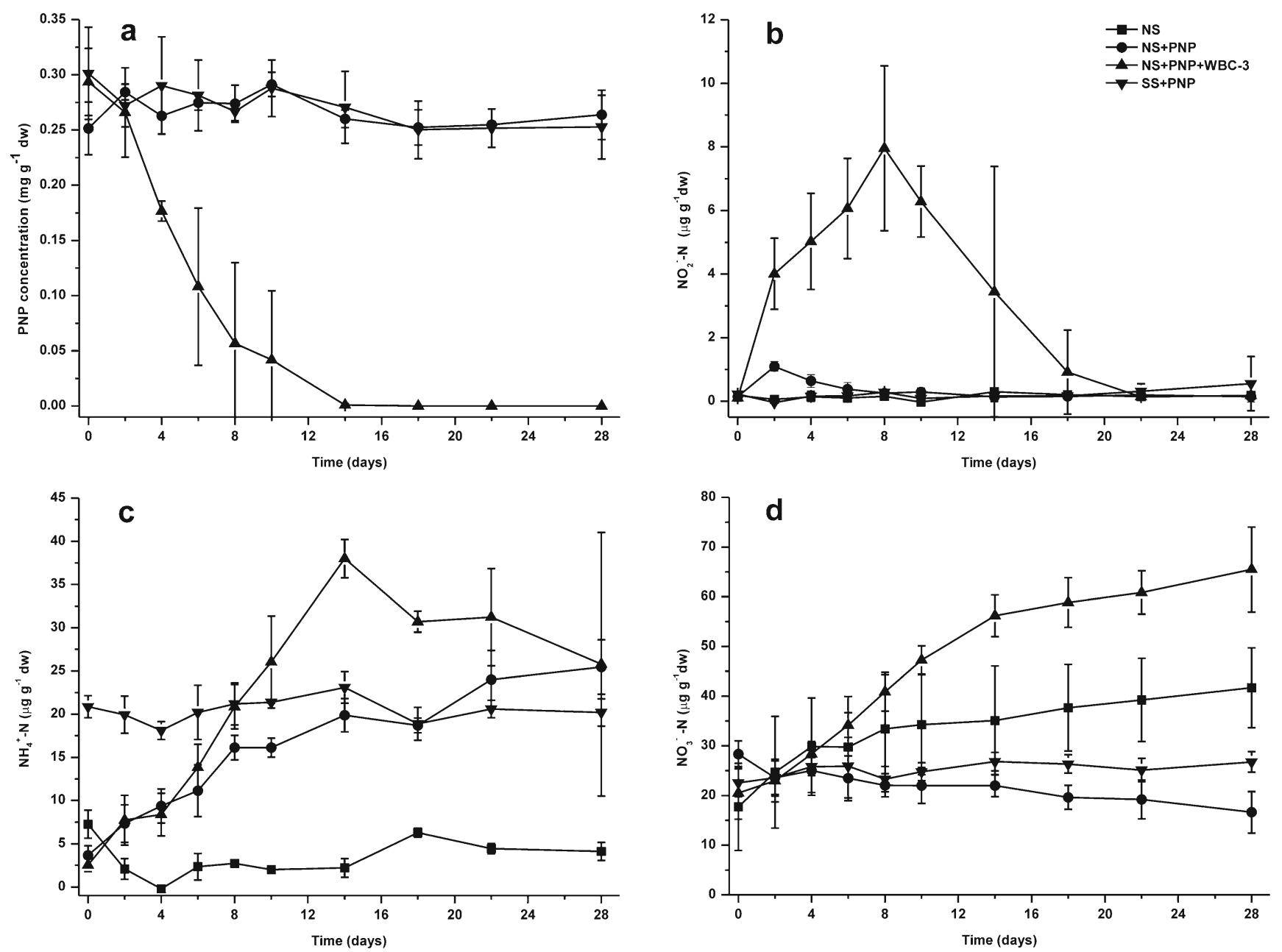

Fig. 1 Chemical analysis during the bioaugmentation process. a Removal of $\mathrm{PNP}, \mathbf{b} \mathrm{NO}_{2}{ }^{-}-\mathrm{N}$ concentration, $\mathbf{c} \mathrm{NH}_{4}{ }^{+}-\mathrm{N}_{\text {concentration, and } \mathbf{d ~ N O}}{ }^{-}-\mathrm{N}$ concentration. Values are means $\pm \mathrm{SD}$ (error bars) $(n=3)$. (NS natural soil, $S S$ sterile soil)

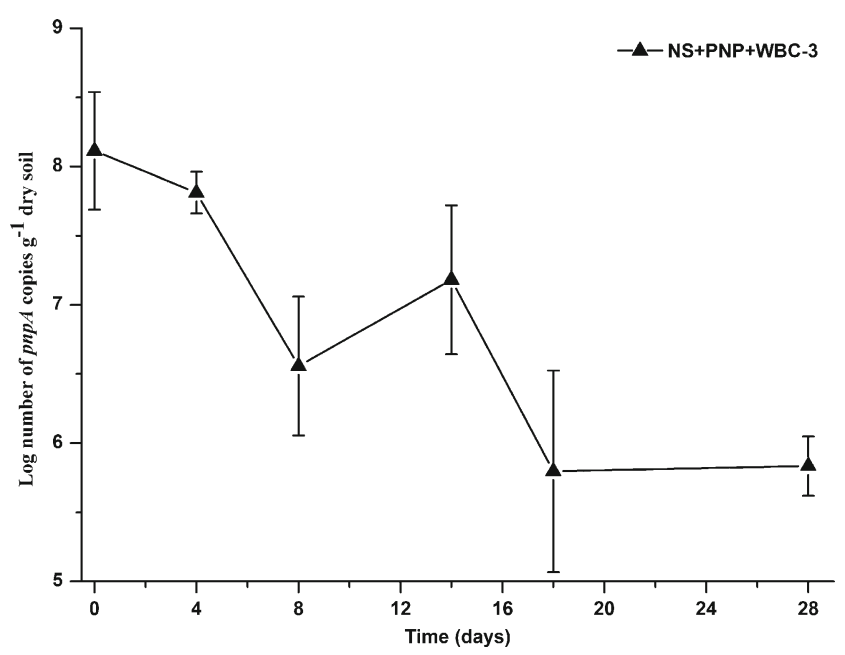

Fig. 2 Quantification of pnpA gene (strain WBC-3) in inoculated soil microcosm by real-time PCR. Values are means $\pm \mathrm{SD}$ (error bars) $(n=3)$. (NS natural soil)
Impact of pollution and bioaugmentation on abundance of $\mathrm{AOB}$ and $\mathrm{AOA}$

The abundance of $\mathrm{AOA}$ and $\mathrm{AOB}$ in non-sterile treatments was quantified using real-time PCR targeting amo $A$ gene. The initial AOA copy numbers of amoA gene in the original soil sample were $1.13 \pm 0.91 \times 10^{6} \mathrm{~g}^{-1} \mathrm{dw}$ (Fig. 3a), one order of

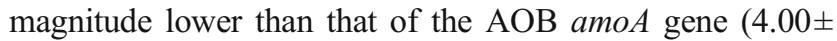
$3.49 \times 10^{7}$ per gram of dry soil) (Fig. 3b). During the 28-day experimental period, the AOA amoA gene abundance in native soil treatment $\mathrm{T} 1$ and PNP contamination treatment $\mathrm{T} 2$ showed no significant variation $(P>0.05)$ (Fig. 3a). In contrast, the differences in the abundance of the AOB amoA gene abundance in treatments $\mathrm{T} 1$ and $\mathrm{T} 2$ was statistically significant $(0.01<P<0.05)$ (Fig. 3b). AOA amoA gene abundance in treatment T2 was significantly higher than in T3 $(P<0.01)$ (Fig. 3a). Similarly, the abundance of AOB amoA gene in T3 was also very significantly lower than in T2 $(P<0.01)$ (Fig. 3b), suggesting that bioaugmentation of PNP-contaminated soil reduced the abundance of $\mathrm{AOA}$ and $\mathrm{AOB}$ greatly. 

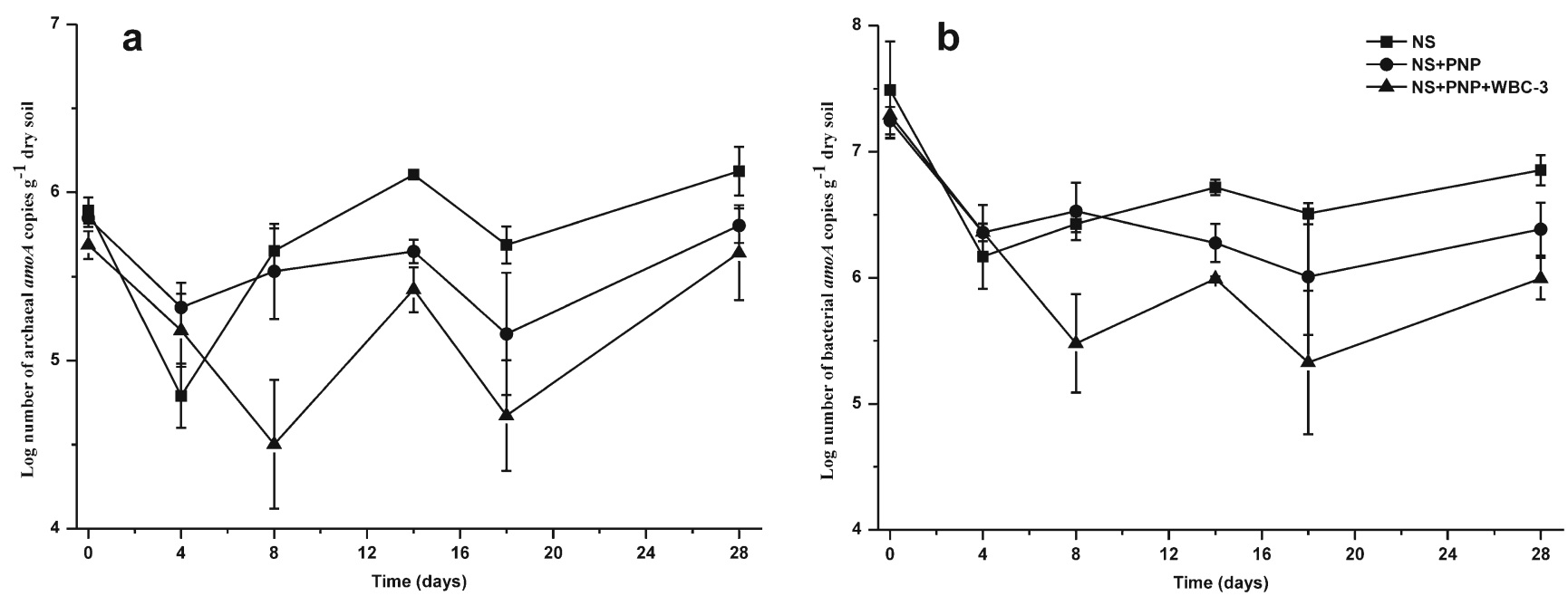

Fig. 3 Quantification of amoA gene in different soil microcosms by real-time PCR. a AOA amoA and $\mathbf{b} \mathrm{AOB}$ amoA. Values are means $\pm \mathrm{SD}$ (error bars) $(n=3)$. (NS natural soil, $S S$ sterile soil)

Impact of PNP contamination on community structure of $\mathrm{AOB}$ and $\mathrm{AOA}$

The effects of PNP contamination and bioaugmentation on community structure of $\mathrm{AOB}$ and $\mathrm{AOA}$ were examined by DGGE profiles targeting the amoA genes in the 0-, 8-, and 28-day samples. The presence of PNP did not bring any evident change in the species richness of AOA community between treatments $\mathrm{T} 1$ and T2 (Fig. 4a). The correlations between the community structure of AOA and environmental parameters were analyzed by multivariate analysis (RDA and pRDA). Standard RDA indicated that $31.9 \%$ of the variance in species could be explained by environmental parameters (both treatment and time) (Fig. 4b). However, the model did not significantly explain the variation of AOA community structure $(P>0.05)$. This indicates that PNP contamination did not significantly influence AOA community structure.

Variation partitioning was also used to evaluate the impact of environmental parameters on $\mathrm{AOB}$ community structure in native soil $\mathrm{T} 1$ and contamination treatment $\mathrm{T} 2$. As shown in Fig. $5 b, 56.4 \%$ of the variance in species was explained by standard RDA in which treatment and time both served as explanatory variables $(P<0.05)$. However, $\mathrm{pRDA}$ (explanatory variable: time, covariable: treatment) indicated that time explained $21.6 \%$ of the variance in species and was statistically significant $(P<0.05)$. pRDA (explanatory variable: treatment, covariable: time) showed that $25.3 \%$ of the variance in species could be explained, but this was not statistically significant $(P>0.05)$ (Fig. 5b), suggesting that the community structure of AOB was significantly affected by the cooperation of both time and treatment (PNP contamination, $\mathrm{NH}_{4}{ }^{+}, \mathrm{NO}_{3}{ }^{-}, \mathrm{NO}_{2}{ }^{-}$, etc.). However, the variation in $\mathrm{AOB}$ community structure was caused mostly by time, not by PNP contamination.
Impact of bioaugmentation on community structure of $\mathrm{AOB}$ and $\mathrm{AOA}$

Analysis of AOA community structure in treatment groups T2 and T3 showed that $55.4 \%$ of the variance in species could be explained by standard RDA in which time and treatments all served as explanatory variables $(P<0.05)$ (Fig. 6b). pRDA (explanatory variable: time, covariable: treatment), however, suggested that $10.5 \%$ of the variance in species was caused by time and that this variance was not statistically significant $(P>0.05)$. pRDA (explanatory variable: treatment, covariable: time) indicated that $20.8 \%$ of the variance was due to species variation, and this variance was not statistically significant $(P>0.05)$ (Fig. 6b). These results indicated that the community structure of AOA was significantly affected by a combination of both time and soil treatment (PNP contamination, strain WBC- $3, \mathrm{NH}_{4}^{+}, \mathrm{NO}_{3}^{-}$, and $\mathrm{NO}_{2}{ }^{-}$, etc.). Figure $6 \mathrm{~b}$ shows the correlation between environmental factors and AOA community structure. The first axis of RDA explained $36.2 \%$ and the second $8.8 \%$ of the variance in species, respectively. The first two axes explained $81.1 \%$ of the cumulative variance of the environment-species correlation.

For the AOB community treatment $\mathrm{T} 2$ and treatment $\mathrm{T} 3$ analyses, standard RDA (both treatment and time as explanatory variables) showed that $72 \%$ of the variance was due to species variation $(P<0.05)$ (Fig. $7 \mathrm{~b}$ ). However, time explained $6.7 \%$ of the variance in species, as determined by pRDA (explanatory variable: time, covariable: treatment), but this variance was not statistically significant $(P>0.05)$ (Fig. 7b). pRDA (explanatory variable: treatment, covariable: time) showed that treatment explained $59.1 \%$ of the variance in species $(P<0.05)$ 


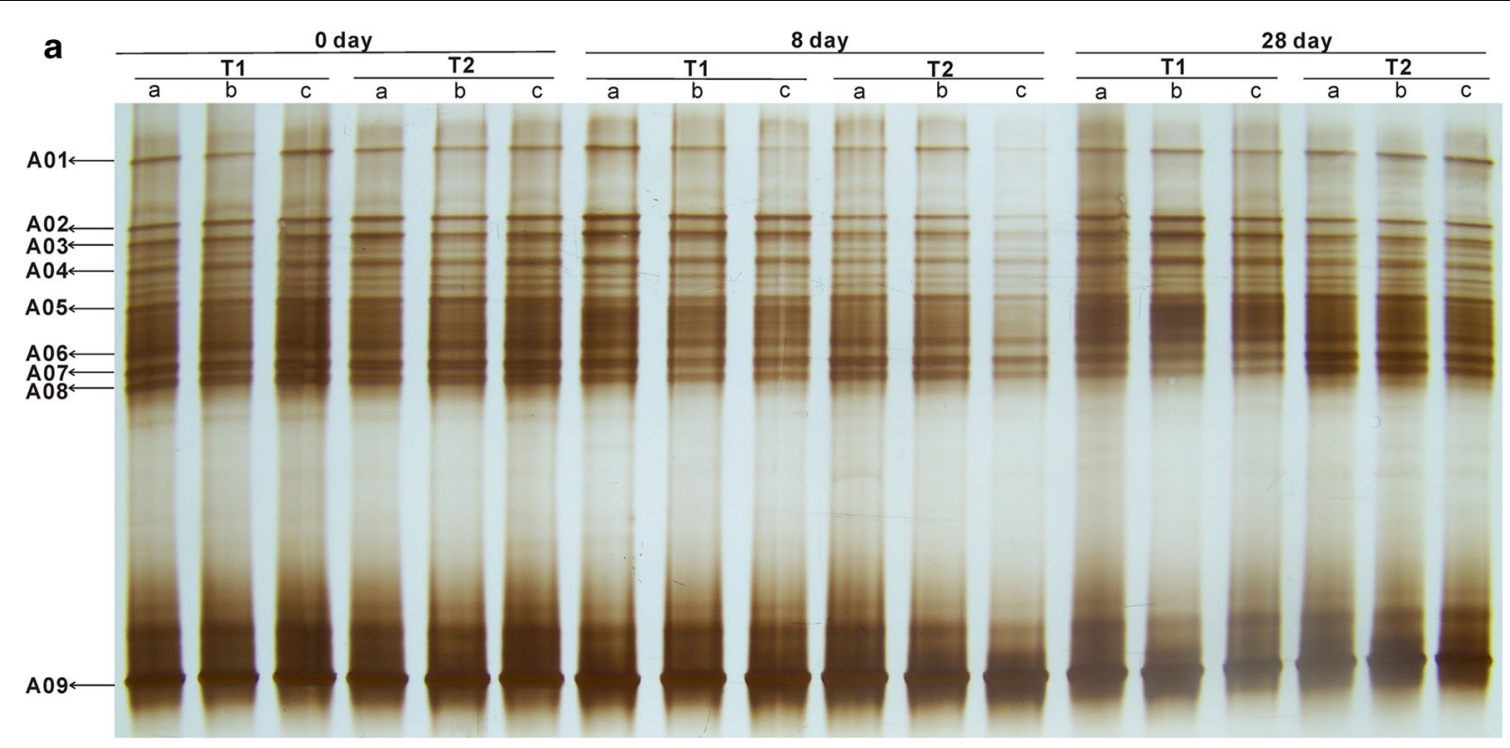

b

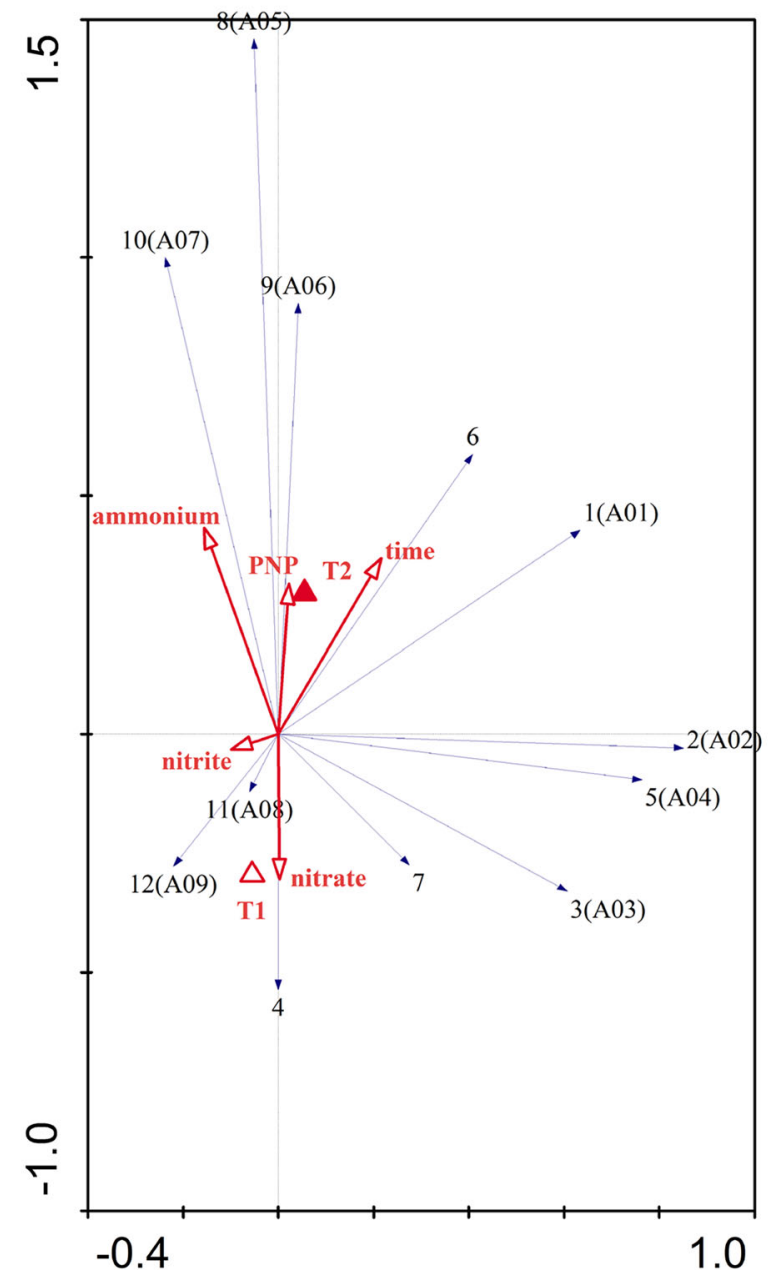

Fig. 4 a Analyses of AOA community structure in control T1 and pollutant T2 based on PCR-DGGE profiles (0, 8, and 28 days). Bands with arrows were excised and then sequenced. $\mathbf{b}$ Ordination biplots based on the RDA analyses of DGGE patterns. Solid arrows represent species; empty arrows represent environmental variables. Empty triangles represent T1; solid triangles represent $\mathrm{T} 2$. Qualitative variables which were plotted according to their centroid location in the graph. The cosine of the angle between the respective arrows indicates the correlation between species composition and environmental parameters. The length of arrow suggests its involvement in the model. The sequenced bands are shown in brackets with band numbers (A01-A09: GenBank accession nos. KM055675-KM055683) 


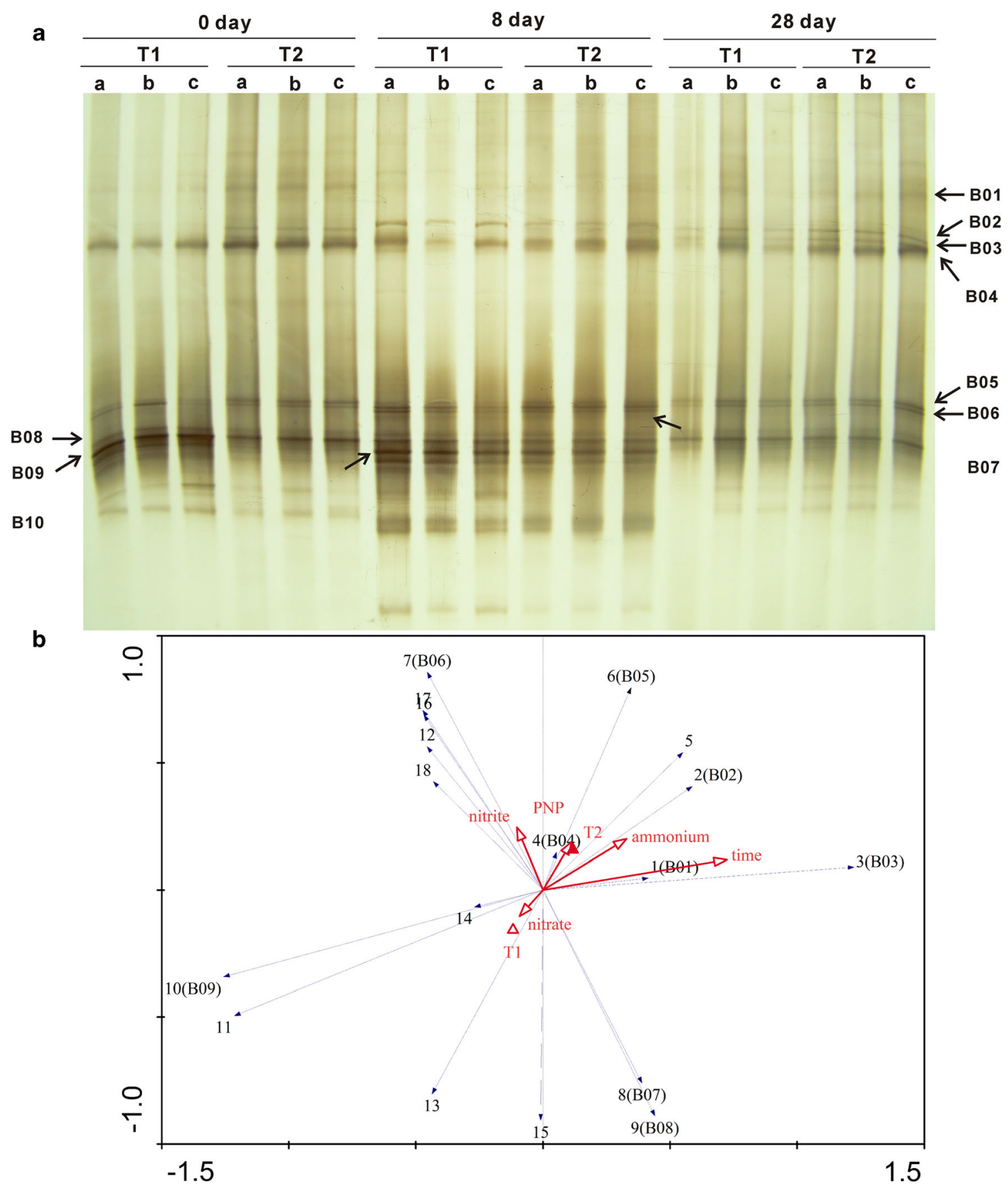

Fig. 5 a Analyses of AOB community structure in control T1 and pollutant T2 based on PCR-DGGE profiles (0, 8, and 28 days). Bands with arrows were excised and then sequenced. $\mathbf{b}$ The description is the

same as in Fig. 4b, and the sequenced bands are shown in brackets with band numbers (B01-B10: GenBank accession nos. KM055656KM055665)

(Fig. 7b). It can therefore be inferred that the changes in community structure of AOB were significantly affected by bioaugmentation treatment. As shown by the biplots in Fig. 7b, the first axis of pRDA (explanatory variable: treatment, covariable: time) accounted for $63.6 \%$ and the second axis for $1.6 \%$ of the variance in species. The first two axes explained $96.1 \%$ of the cumulative variance of the environment-species correlation (Fig. $7 \mathrm{~b}$ ). $\mathrm{NH}_{4}^{+}$was the primary factor among the studied treatment variables (PNP, $\mathrm{NH}_{4}^{+}, \mathrm{NO}_{2}{ }^{-}, \mathrm{NO}_{3}{ }^{-}$, and strain WBC-3) and affected the $\mathrm{AOB}$ community structure as shown by pRDA analysis. $\mathrm{NH}_{4}^{+}$was found to be positively correlated with both $\mathrm{NO}_{2}{ }^{-}$and $\mathrm{NO}_{3}{ }^{-}$but negatively correlated with both strain WBC-3 and PNP. pRDA showed that inoculation with 


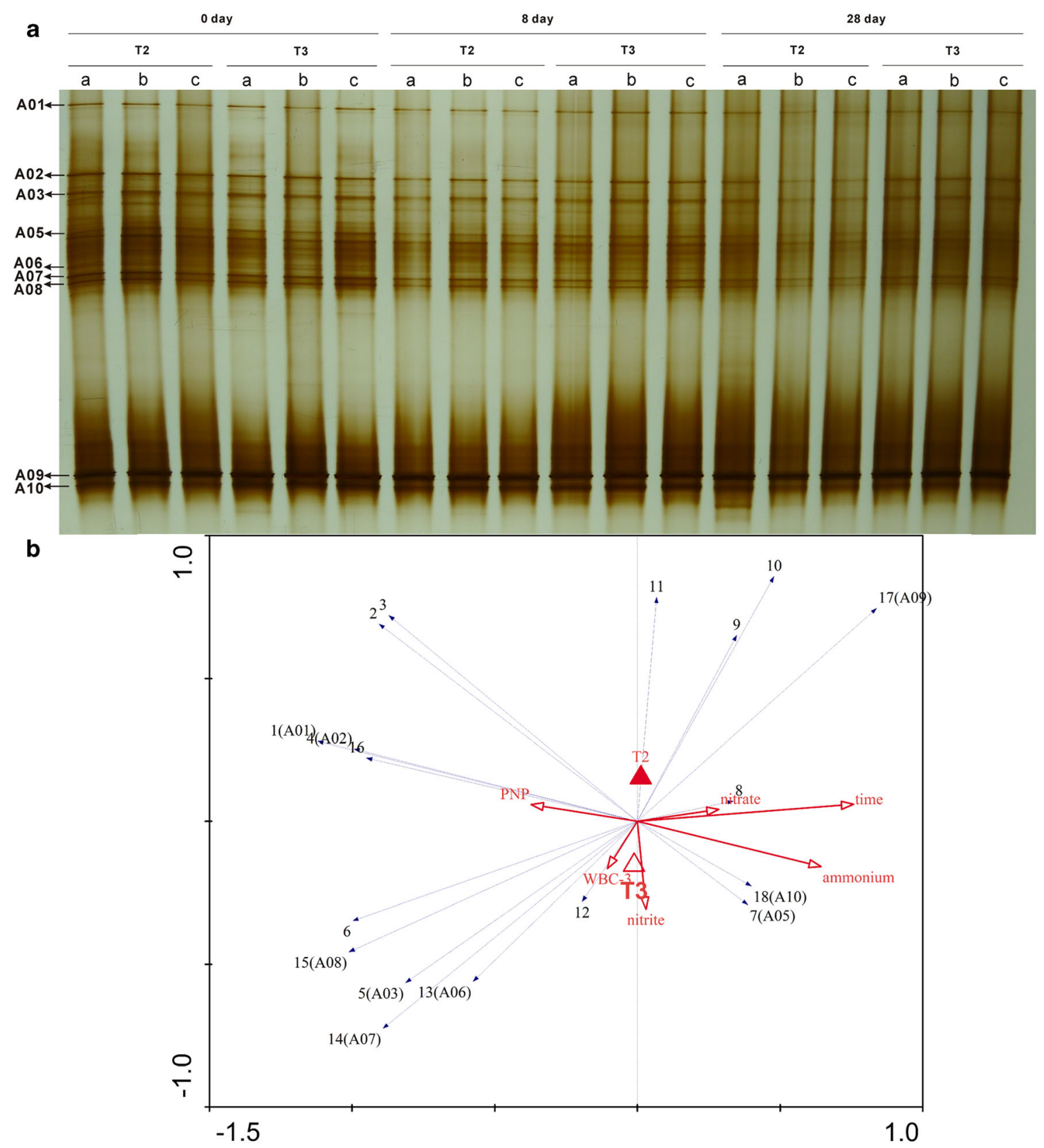

Fig. 6 a Analyses of AOA community structure in pollutant T2 and bioaugmentation T3 based on PCR-DGGE profiles ( 0,8 , and 28 days). Bands with arrows were excised and then sequenced. $\mathbf{b}$ The description is

the same as in Fig. 4b, and the sequenced bands are shown in brackets with band numbers (A01-A10: GenBank accession nos. KM055675KM055684)

strain WBC-3 is also an important determining factor (next to $\mathrm{NH}_{4}{ }^{+}$) affecting the $\mathrm{AOB}$ community structure variation.

Genetic profiling of the amoA genes of AOB and AOA

The same numbers were used to mark bands that shared the same position in the DGGE gels, and those bands were excised for subsequent phylogenetic analysis. DGGE profiles of AOA showed that all 10 bands (A01-A10, GenBank accession nos. KM055675-KM055684) of AOA amoA genes belonged to cluster $\mathrm{S}$ (groups dominated by sequences extracted from soil) designated previously (He et al. 2007; Shen et al. 2008) (Figs. 4a and 6a), and cluster M refers to groups dominated by sequences extracted from marine environments (Fig. 8). The most similar sequences in GenBank to the 10 band sequences were mostly from flooded soil or bioreactors. The soil samples in this work were taken from a paddy soil that is flooded with water for several months every year. All AOB sequences (B01-B17-2, GenBank accession nos. 
a

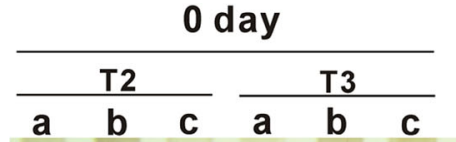

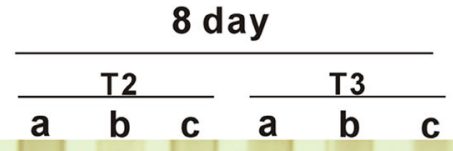

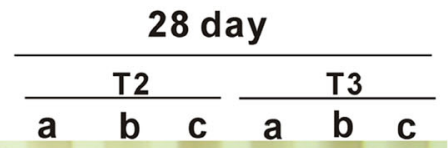

B11

B12
B13 $\rightarrow$

B14

B17

$\rightarrow$

\section{B15 $\rightarrow$
B16 $\rightarrow$ \\ B15 $\rightarrow$
B16 $\rightarrow$}

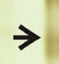

b

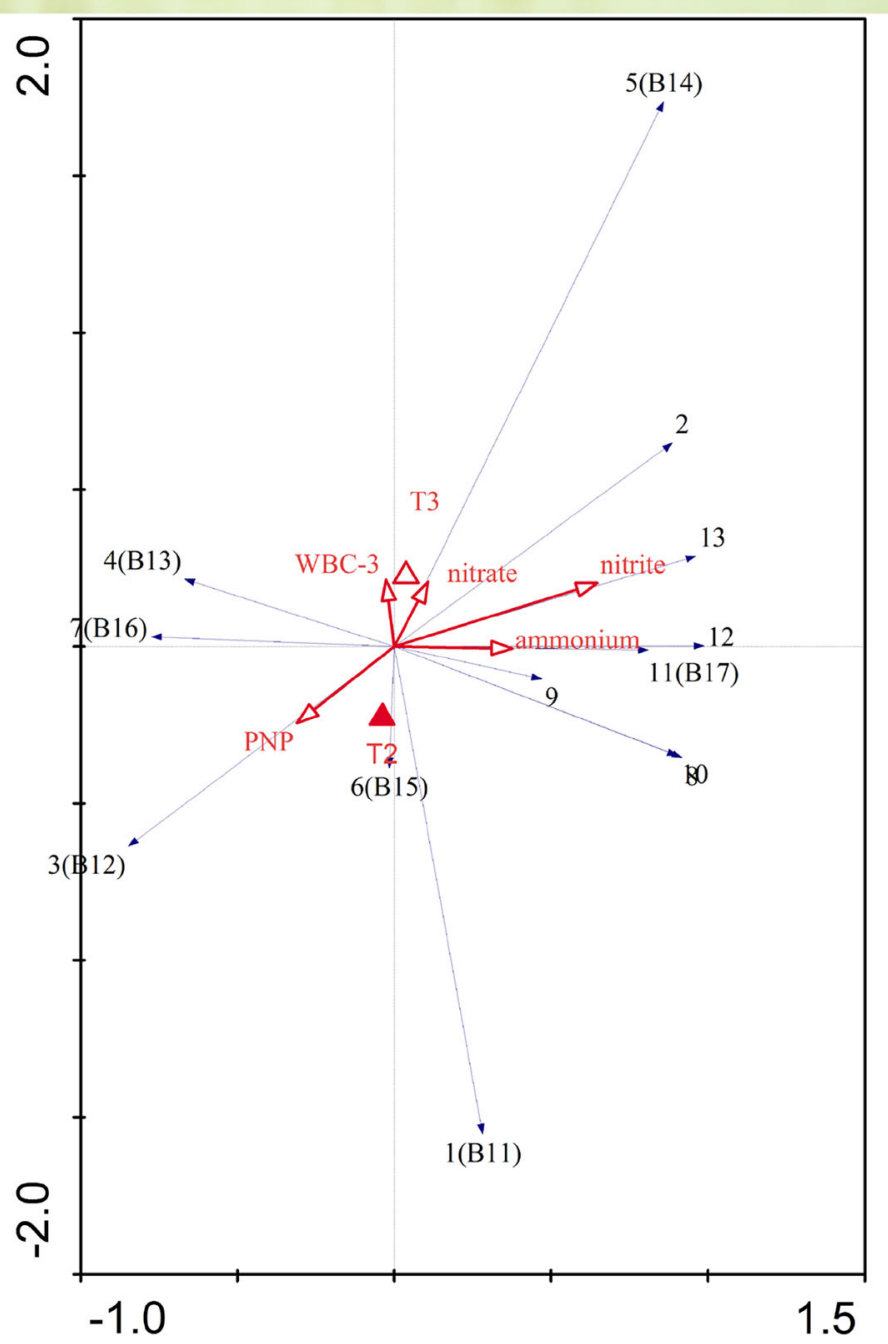


Fig. 7 a Analyses of $\mathrm{AOB}$ community structure in pollutant $\mathrm{T} 2$ and bioaugmentation T3 based on PCR-DGGE profiles ( 0,8 , and 28 days). Bands with arrows were excised and then sequenced. $\mathbf{b}$ The description is the same as in Fig. 4b, and the sequenced bands are shown in brackets with band numbers (B11-B17: GenBank accession nos. KM055667KM055673)

KM055656-KM055674) were affiliated with the genus Nitrosospira and grouped into clusters 3a, 3c, 4, and 9 (Figs. 5a, 7a, and 9), as indicated by phylogenetic analyses of AOB amo $A$ gene sequences ( $2 \%$ nucleotide cutoffs). The AOB amoA clusters were classified as described in previous studies (Avrhami and Conrad 2003; He et al. 2007).

\section{Discussion}

When PNP is degraded by strain WBC-3 with subsequent $\mathrm{NO}_{2}{ }^{-}$release in soil, it is probable that PNP contamination and bioaugmentation could be involved in the nitrification process and the nitrogen cycling. This involvement may initiate a corresponding response of $\mathrm{AOB}$ and $\mathrm{AOA}$ to the environmental change and their new niche partitioning. Up to present, there has been only a single example of the influences of bioaugmentation processes on $\mathrm{AOB}$ community structure in soil (Zhao et al. 2009), but at present, the corresponding responses of significant groups of AOA have not been reported. The current study focused on the effect of PNP contamination and bioaugmentation on the populations and community structures of both groups of $\mathrm{AOB}$ and $\mathrm{AOA}$ to determine the respective dominance and niche segregation of ammonia oxidizers under the above dynamic biological conditions.

Both the catabolic capability of the inoculated strains and their existence in polluted soil were essential to successful bioaugmentation (Cunliffe and Kertesz 2006; Singer et al. 2005). The inoculated strain WBC-3 used in the current study was found to play a critical role in the removal of PNP from soil, as indicated by the much higher rate of PNP removal and greater accumulation of $\mathrm{NO}_{2}^{-}$in treatment $\mathrm{T} 3$ than in treatment groups T2 and T4. It is generally accepted that poor survival of adventitious degraders may cause bioaugmentation to failure (Bouchez et al. 2000). In this study, changes in the abundance of strain WBC-3 during the degradation period and its subsequent stabilization afterwards suggested that the inoculated strain WBC-3 could still use local resources in soil after PNP had been completely depleted, after which a new community developed.

Nitrification is essential to the nitrogen cycling in agricultural paddy soils. In the original soil sample used, the abundance of $\mathrm{AOB}$ was two orders of magnitude higher than that of AOA. This indicated that AOB predominated over AOA

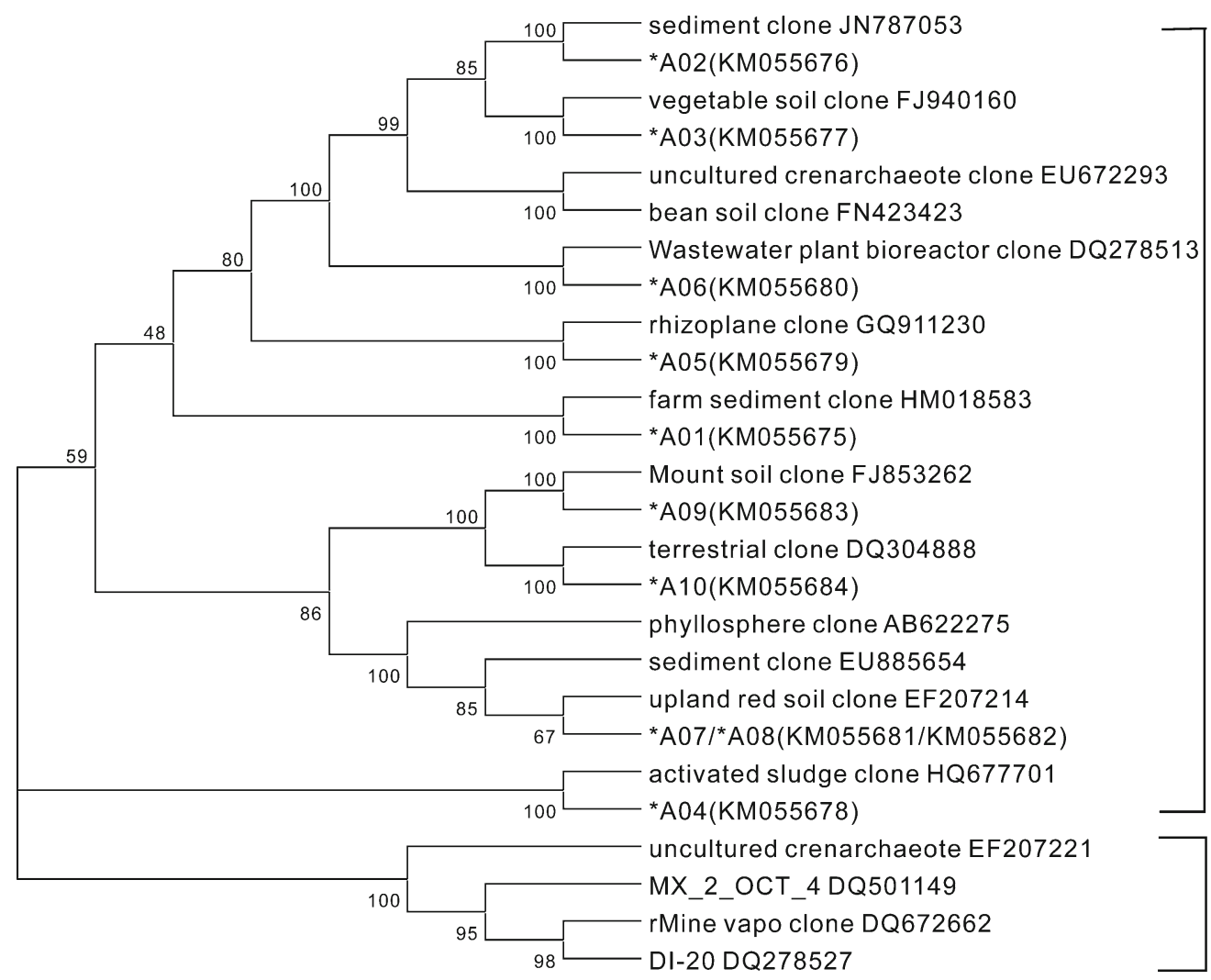

Cluster S

Fig. 8 Phylogenetic relationships of archaeal amoA sequences retrieved from current study with those from archaea in GenBank. The name of each sequence is followed by a GenBank accession number, and those from current study are marked by an asterisk (A01-A10: GenBank accession nos. KM055675-KM055684). Bootstrap value (>48 \%) are shown at nodes 


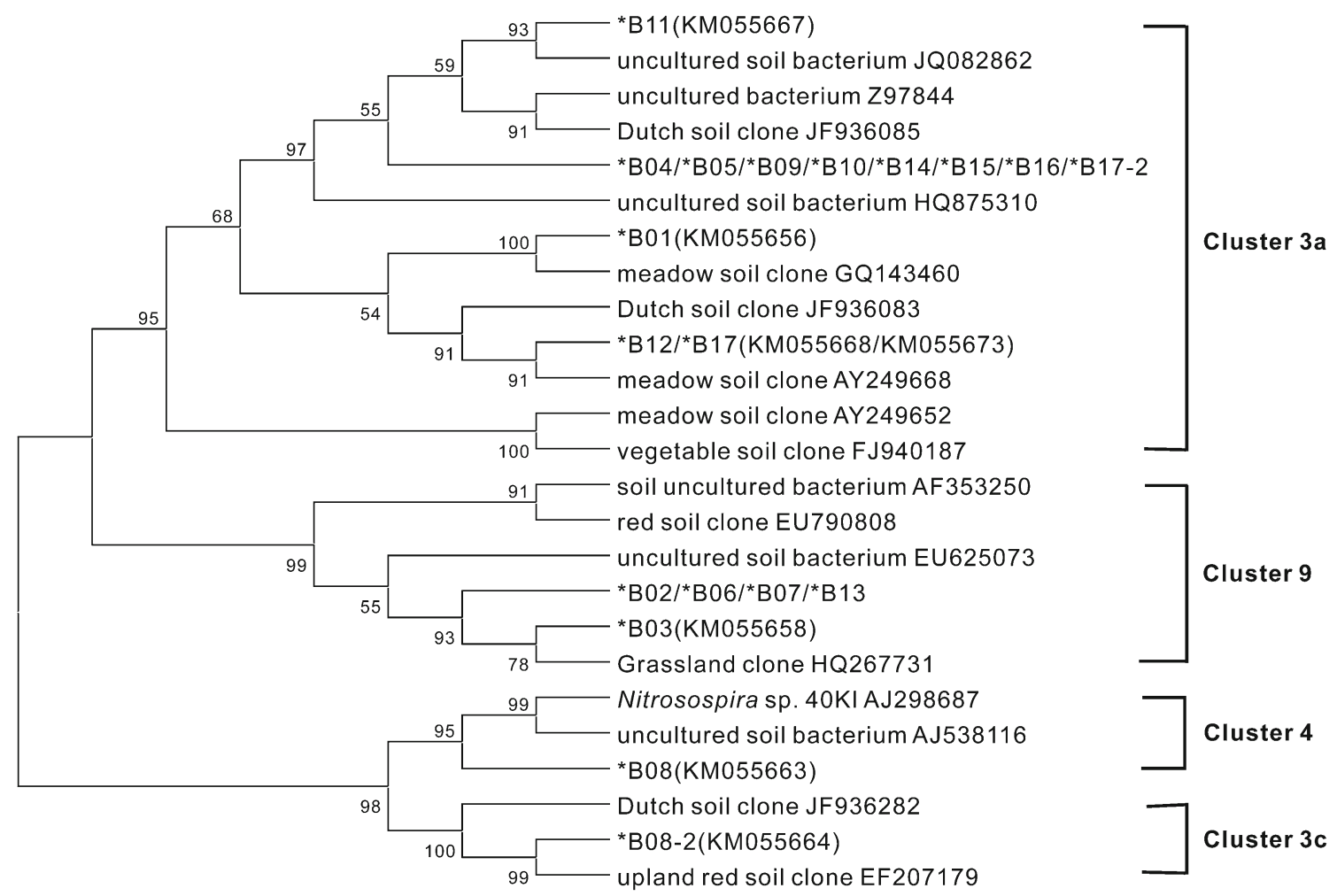

Fig. 9 Phylogenetic relationships of bacterial amoA sequences retrieved from current study with those from bacteria in GenBank. The name of each sequence is followed by a GenBank accession number, and those

and so played a greater role in nitrification than AOA. It has previously been reported that, in acidic soils, ammonia oxidation may be largely attributable to AOA, but AOB performs better in alkaline or neutral soils (Nicol et al. 2008). DNAstable isotope probing has provided direct evidences that ammonia oxidation in acidic soils is driven by AOA rather than AOB (Zhang et al. 2012). In the current study, the original paddy soil had a neutral $\mathrm{pH}$. The observed dominance of AOB over AOA was consistent with the previous findings.

Organic pollutants, especially cyclic $\mathrm{N}$ compounds, have been reported to reduce soil nitrification (Keener and Arp 1994; McCarty 1999; Zhao et al. 2009). In the current study, PNP contamination did not significantly alter the abundance and community structure of ammonia oxidizers except for inhibiting the AOB abundance. These results suggest that the AOA group is not significantly sensitive to PNP toxicity. However, the decrease in $\mathrm{NO}_{3}{ }^{-}$contaminant with the increase in $\mathrm{NH}_{4}{ }^{+}$in treatment $\mathrm{T} 2$ implied that nitrification had been inhibited. The reduction of $\mathrm{AOB}$ abundance indicated that $\mathrm{AOB}$ were primarily responsible for the nitrification process in this habitat. This conclusion was consistent with the predominance of AOB population over AOA in the original soil samples.

In contrast, bioaugmentation of PNP-contaminated soil significantly affected the population and community structure of $\mathrm{AOB}$ and the population of AOA. However, there was no significant impact on AOA community structure. This was from current study are marked by an asterisk (B01-B17-2: GenBank accession nos. KM055656-KM055674). Bootstrap value (>50\%) are shown at nodes

most likely due to significant variations in $\mathrm{NH}_{4}{ }^{+}$concentration. Multivariate analysis showed $\mathrm{NH}_{4}{ }^{+}$to be the primary factor affecting the community structure of ammonia oxidizers. Several reports have stated the importance of $\mathrm{NH}_{4}{ }^{+}$ in nitrification. For example, the kinetics of ammonia oxidation was reported to determine the niche partitioning of $\mathrm{AOB}$ and AOA (Martens-Habbena et al. 2009). $\mathrm{NH}_{4}{ }^{+}$concentration can also determine the differential growth of $\mathrm{AOB}$ and $\mathrm{AOA}$ in soil in that AOA prefers a less $\mathrm{NH}_{4}^{+}$(Verhamme et al. 2011). An increase in $\mathrm{NH}_{4}{ }^{+}$concentration is indicative of a reduced nitrification efficiency (Abell et al. 2011). In treatment $\mathrm{T} 3$ in the present study, the $\mathrm{NH}_{4}{ }^{+}$concentration increased as that of $\mathrm{NO}_{2}{ }^{-}$increased after PNP degradation by strain WBC-3. This was apparently responsible for the significant inhibition of $\mathrm{AOB}$ and $\mathrm{AOA}$ abundance and significant effects on the AOB community structure. The increase in $\mathrm{NH}_{4}{ }^{+}$during the increase in $\mathrm{NO}_{2}^{-}$in group $\mathrm{T} 3$ could be attributable to the release of $\mathrm{NH}_{4}^{+}$by the inoculated strain WBC-3 and indigenous microorganisms during growth or that some indigenous microorganisms can also utilize PNP but via a reductive pathway which releases $\mathrm{NH}_{4}^{+}$.

In the original soil sample, AOB predominated over AOA and was considered the primary contributor to the nitrification process. In the presence of PNP toxicity, the AOB population was significantly inhibited, but the less active AOA group was unaffected by the disturbance. Furthermore, only when the 
$\mathrm{NH}_{4}^{+}$(as the substrate of ammonia oxidation) concentration changed greatly in treatment $\mathrm{T} 3$ was AOA abundance reduced significantly. Its community composition was not influenced in any visible way. These results indicated that AOA is probably more stable under environmental stresses introduced than $\mathrm{AOB}$ and adapted more readily to severe environments. Previous reports have indicated that the AOA could grow well in nutrient-insufficient environments while AOB favored high-energy environments (Hofferle et al. 2010). It has also been demonstrated that AOB and AOA may be active under the same conditions, with both groups competing against each other. This may be due to functional redundancy or fundamental physiological differences that produce distinct ecological niches (Verhamme et al. 2011). In the current study, when oxygen supply and ammonia oxidation were adequate during the rape planting season, which did not involve flooding, the AOA were less active than the AOB. However, the current study showed that the balance between archaeal and bacterial ammonia oxidation can be affected by other factors, such as $\mathrm{NH}_{4}^{+}$variation.

In the current study, a laboratory experiment, rather than a field experiment, was performed so that the responses of $\mathrm{AOB}$ and AOA to PNP contamination and bioaugmentation processes would be assessed in a controllable environment. However, the results of the laboratory experiment may not coincide exactly with those collected in real field environments. This current study may provide some knowledge of AOB and AOA responses to PNP in the paddy soil used. More soil types and the real field experimental settings are necessary to indicate the responses more accurately and comprehensively.

In addition, information regarding the diversity and community structure analyzed from DGGE approach in the current study is limited, but this may be rectified using nextgeneration sequencing techniques. Next-generation sequencing techniques have been developing rapidly and are being considered for use in assessments of the effects of PNP or other similar compounds on microbial communities and the studying microbial degradation of pollutants. Nextgeneration sequencing techniques based on the $16 \mathrm{~S}$ rRNA gene and special functional genes (such as amoA gene in the current study) may facilitate more abundant and representative studies of these species and their functional genes. The response of microbial community structure and diversity to the PNP and other similar compounds could be evaluated comprehensively. It is possible that some new functional species capable of degrading the pollutants or actively responsible to the pollutants will be found.

Acknowledgments This work is supported by the National Natural Science Foundation of China (21077130).

Conflict of interest We declare that we have no conflicts of interest.

\section{References}

Abell GCJ, Banks J, Ross DJ, Keane JP, Robert SS, Revill AT, Volkman JK (2011) Effects of estuarine sediment hypoxia on nitrogen fluxes and ammonia oxidizer gene transcription. FEMS Microbiol Ecol 75: 111-122. doi:10.1111/j.1574-6941.2010.00988.x

Avrhami S, Conrad R (2003) Patterns of community change among ammonia oxidizers in meadow soils upon long-term incubation at different temperatures. Appl Environ Microbiol 69:6152-6164. doi:10. 1128/aem. 69.10.6152-6164.2003

Bouchez T, Patureau D, Dabert P, Juretschko S, Dore J, Delgenes P, Moletta R, Wagner M (2000) Ecological study of a bioaugmentation failure. Environ Microbiol 2:179-190. doi:10.1046/j.1462-2920. 2000.00091.x

Chi XQ, Zhang JJ, Zhao S, Zhou NY (2013) Bioaugmentation with a consortium of bacterial nitrophenol-degraders for remediation of soil contaminated with three nitrophenol isomers. Environ Pollut 172:33-41. doi:10.1016/j.envpol.2012.08.002

Cunliffe M, Kertesz MA (2006) Effect of Sphingobium-yanoikuyae B1 inoculation on bacterial community dynamics and polycyclic aromatic hydrocarbon degradation in aged and freshly $\mathrm{PAH}-$ contaminated soils. Environ Pollut 144:228-237. doi:10.1016/j. envpol.2005.12.026

Dechesne A, Pallud C, Bertolla F, Grundmann GL (2005) Impact of the microscale distribution of a Pseudomonas strain introduced into soil on potential contacts with indigenous bacteria. Appl Environ Microbiol 71:8123-8131. doi:10.1128/aem. 71.12.8123-8131.2005

Fawcett JK, Scott JE (1960) A rapid and precise method for the determination of urea. J Clin Pathol 13:156-159. doi:10.1136/jcp.13.2.156

Guo XF, Wang ZH, Zhou SP (2004) The separation and determination of nitrophenol isomers by high-performance capillary zone electrophoresis. Talanta 64:135-139. doi:10.1016/j.talanta.2004.01.020

He JZ, Shen JP, Zhang LM, Zhu YG, Zheng YM, Xu MG, Di HJ (2007) Quantitative analyses of the abundance and composition of ammonia-oxidizing bacteria and ammonia-oxidizing archaea of a Chinese upland red soil under long-term fertilization practices 9: 2364, 2007. Environ Microbiol 9:3152. doi:10.1111/j.1462-2920. 2007.01481.x

Hofferle S, Nicol GW, Pal L, Hacin J, Prosser JI, Mandic-Mulec I (2010) Ammonium supply rate influences archaeal and bacterial ammonia oxidizers in a wetland soil vertical profile. FEMS Microbiol Ecol 74: 302-315. doi:10.1111/j.1574-6941.2010.00961.x

Keener WK, Arp DJ (1994) Transformations of aromatic-compounds by nitrosomonas-europaea. Appl Environ Microbiol 60:1914-1920

Keith LH, Telliard WA (1979) Priority pollutants I-A perspective view. Environ Sci Technol 13:416-423. doi:10.1021/es60152a601

Labana S, Pandey G, Paul D, Sharma NK, Basu A, Jain RK (2005) Pot and field studies on bioremediation of $p$-nitrophenol contaminated soil using Arthrobacter protophormiae RKJ100. Environ Sci Technol 39:3330-3337. doi:10.1021/es0489801

Lessner DJ, Johnson GR, Parales RE, Spain JC, Gibson DT (2002) Molecular characterization and substrate specificity of nitrobenzene dioxygenase from Comamonas sp. strain JS765. Appl Environ Microbiol 68:634-641. doi:10.1128/aem. 68.2.634-641.2002

Liu S, Shen L, Lou L, Tian G, Zheng P, Hu B (2013) Spatial distribution and factors shaping the niche segregation of ammonia-oxidizing microorganisms in the Qiantang River, China. Appl Environ Microbiol 79:4065-4071. doi:10.1128/aem. 00543-13

Martens-Habbena W, Berube PM, Urakawa H, de la Torre JR, Stahl DA (2009) Ammonia oxidation kinetics determine niche separation of nitrifying Archaea and Bacteria. Nature 461:976-979. doi:10.1038/ nature 08465

McCaig AE, Glover LA, Prosser JI (2001) Numerical analysis of grassland bacterial community structure under different land management regimens by using $16 \mathrm{~S}$ ribosomal DNA sequence data and 
denaturing gradient gel electrophoresis banding patterns. Appl Environ Microbiol 67:4554-4559. doi:10.1128/aem. 67.10.45544559.2001

McCarty GW (1999) Modes of action of nitrification inhibitors. Biol Fertil Soils 29:1-9. doi:10.1007/s003740050518

Mosier AC, Francis CA (2008) Relative abundance and diversity of ammonia-oxidizing archaea and bacteria in the San Francisco Bay estuary. Environ Microbiol 10:3002-3016. doi:10.1111/j.14622920.2008.01764.x

Muyzer G, Dewaal EC, Uitterlinden AG (1993) Profiling of complex microbial-populations by denaturing gradient gel-electrophoresis analysis of polymerase chain reaction-amplified genes-coding for 16S ribosomal-RNA. Appl Environ Microbiol 59:695-700

Nicol GW, Leininger S, Schleper C, Prosser JI (2008) The influence of soil $\mathrm{pH}$ on the diversity, abundance and transcriptional activity of ammonia oxidizing archaea and bacteria. Environ Microbiol 10: 2966-2978. doi:10.1111/j.1462-2920.2008.01701.x

Norman RJ, Edberg JC, Stucki JW (1985) Determination of nitrate in soil extracts by dual wavelength ultraviolet spectrophotometry. Soil Sci Soc Am J 49:1182-1185

Prosser JI, Nicol GW (2012) Archaeal and bacterial ammonia-oxidisers in soil: the quest for niche specialisation and differentiation. Trends Microbiol 20:523-531. doi:10.1016/j.tim.2012.08.001

Sahan E, Muyzer G (2008) Diversity and spatio-temporal distribution of ammonia-oxidizing Archaea and Bacteria in sediments of the Westerschelde estuary. FEMS Microbiol Ecol 64:175-186. doi:10. $1111 / j .1574-6941.2008 .00462 . x$

Schwieger F, Tebbe CC (1998) A new approach to utilize PCRsingle-strand-conformation polymorphism for 16S rRNA genebased microbial community analysis. Appl Environ Microbiol 64:4870-4876
Shen JP, Zhang LM, Zhu YG, Zhang JB, He JZ (2008) Abundance and composition of ammonia-oxidizing bacteria and ammonia-oxidizing archaea communities of an alkaline sandy loam. Environ Microbiol 10:1601-1611. doi:10.1111/j.1462-2920.2008.01578.x

Singer AC, van der Gast CJ, Thompson IP (2005) Perspectives and vision for strain selection in bioaugmentation. Trends Biotechnol 23:74 77. doi:10.1016/j.tibtech.2004.12.012

Sverdrup LE, Ekelund F, Krogh PH, Nielsen T, Johnsen K (2002) Soil microbial toxicity of eight polycyclic aromatic compounds: effects on nitrification, the genetic diversity of bacteria, and the total number of protozoans. Environ Toxicol Chem 21:1644-1650. doi:10. $1897 / 1551-5028$

Verhamme DT, Prosser J, Nicol GW (2011) Ammonia concentration determines differential growth of ammonia-oxidising archaea and bacteria in soil microcosms. ISME J 5:1067-1071. doi:10.1038/ismej.2010.191

Wuchter C, Abbas B, Coolen MJL, Herfort L, van Bleijswijk J, Timmers P, Strous M, Teira E, Herndl GJ, Middelburg JJ (2006) Archaeal nitrification in the ocean. PNAS 103:12317-12322. doi:10.1073/ pnas.0600756103

Zhang JJ, Liu H, Xiao Y, Zhang XE, Zhou NY (2009) Identification and characterization of catabolic para-nitrophenol 4-monooxygenase and para-benzoquinone reductase from Pseudomonas sp. Strain WBC-3. J Bacteriol 191:2703-2710. doi:10.1128/jb.01566-08

Zhang LM, Hu HW, Shen JP, He JZ (2012) Ammonia-oxidizing archaea have more important role than ammonia-oxidizing bacteria in ammonia oxidation of strongly acidic soils. ISME J 6:1032-1045. doi: 10.1038/ismej.2011.168

Zhao S, Ramette A, Niu GL, Liu H, Zhou NY (2009) Effects of nitrobenzene contamination and of bioaugmentation on nitrification and ammonia-oxidizing bacteria in soil. FEMS Microbiol Ecol 70:315323. doi:10.1111/j.1574-6941.2009.00773.x 